\title{
SCIT with a high-dose house dust mite allergoid is well tolerated: safety data from pooled clinical trials and more than 10 years of daily practice analyzed in different subgroups
}

\author{
Ludger Klimek · Gabriele-Cornelia Fox · Susanne Thum-Oltmer
}

Received: 9 January 2018 / Accepted: 8 March 2018

(C) The Author(s) 2018

\begin{abstract}
Background Efficacy of house dust mite (HDM) allergen immunotherapy (AIT) in allergic rhinitis and controlled allergic asthma has been documented in controlled trials with adults and children. However, tolerability comparing clinical development and post marketing data, particularly in different subgroups, is missing.

Methods We performed an analysis of pooled safety data for subcutaneous AIT (SCIT) with a high-dose house dust mite allergoid from 6 randomized, controlled trials (RCT) in HDM allergic respiratory disease (ARD) and of post marketing safety data from more than 10 years including different subgroups (age, gender, asthma status).

Results In all, 500 patients with ARD were treated in RCTs: 279 received the marketed dose of 1800 protein nitrogen units (PNU) high-dose HDM allergoid AIT (214 double-blind placebo controlled [HDMDBPC], 65 children/adolescents usual care controlled [HDM-RCT(UC)]), and 221 placebo (PL). 38.8\% ad-
\end{abstract}

All authors concur with the submission.

Author contributions G.-C. Fox, S. Thum-Oltmer, L. Klimek were involved in manuscript conception and interpretation of the data. G.-C. Fox performed the data analysis. S. Thum-Oltmer prepared figures and substantially contributed to the manuscript from the first draft stage. L. Klimek supervised and participated in writing the manuscript. G.-C. Fox, S. Thum-Oltmer, L. Klimek reviewed, commented and approved the final manuscript.

Prof. L. Klimek, MD $(\bowtie)$

Center for Rhinology and Allergology, An den

Quellen 10, 65183 Wiesbaden, Germany

Ludger.Klimek@allergiezentrum.org

Dr. G.-C. Fox, PhD · Dr. S. Thum-Oltmer, VD

Allergopharma GmbH \& Co. KG, Reinbek bei Hamburg, Germany verse events (AEs) were observed with 1800 PNU in HDM-DBPC (31.2\% PL, 35.5\% HDM-ALL [1800 PNU]); the difference was primarily because of local reactions; there was no difference in systemic reactions (10.9\% PL, 11.2\% HDM-DBPC, 11.2\% HDM-ALL); one out of 279 high-dose HDM allergoid-treated patients had a serious adverse event (SAE).

Children $(n=39)$ /adolescents $(n=26)$ had fewer related AEs and local reactions compared to adults; systemic reactions: children $12.8 \%$, adults $11.2 \%$ adolescents $7.7 \%$. Females had slightly more AEs. Treatment was well tolerated in asthmatic patients $(n=267$; GINA I $n=32$, II $n=104$, III $n=17,114$ no classification).

In more than 10 years more than 100,000 patients were treated with high-dose HDM allergoid (1800 PNU) under daily practice conditions. Adverse drug reactions (ADRs) were reported in $0.5 \%$ of patients. $94.6 \%$ of these ADRs were expected.

Conclusion SCIT with the marketed dose of high-dose HDM allergoid was well tolerated in clinical development and in daily practice. There was no increased risk for the investigated patient subgroups. Tolerability was comparable to HDM sublingual immunotherapy (SLIT) tablets.

Keywords Tolerability - Subcutaneous allergen immunotherapy · Allergic rhinitis · Asthma · Children

$\begin{array}{ll}\text { Abbreviations } \\ \text { AA } & \text { Allergic asthma } \\ \text { ADR } & \text { Adverse drug reaction } \\ \text { AE } & \text { Adverse event } \\ \text { AIT } & \text { Allergen immunotherapy } \\ \text { AR } & \text { Allergic rhinitis } \\ \text { ARD } & \text { Allergic respiratory disease } \\ \text { DBPC } & \text { Double-blind placebo controlled } \\ \text { FEV }_{1} & \text { Forced expiratory flow in } 1 \mathrm{sec}\end{array}$




$\begin{array}{ll}\text { GINA } & \text { Global Initiative for Asthma } \\ \text { HDM } & \text { House dust mite } \\ \text { HDM-ALL } & \text { HDM-DBPC plus HDM-RCT(UC) } \\ \text { PEF } & \text { Peak expiratory flow } \\ \text { PL } & \text { Placebo } \\ \text { PNU } & \text { Protein nitrogen units } \\ \text { RCT } & \text { Randomized, controlled trials } \\ \text { SAE } & \text { Serious adverse event } \\ \text { SCIT } & \text { Subcutaneous immunotherapy } \\ \text { SLIT } & \text { Sublingual immunotherapy } \\ \text { SOC } & \text { System organ class } \\ \text { TRAE } & \text { Treatment-related adverse event } \\ \text { UC } & \text { Usual care }\end{array}$

\section{Introduction}

Allergen immunotherapy (AIT) is a therapy with disease-modifying effects and the only available treatment to target the disease instead of the symptoms. By administering allergen extracts, specific blocking antibodies, tolerance-inducing cells, and mediators are activated. These prevent further exacerbation of the allergen-triggered immune response, block the specific immune response, and attenuate the inflammatory response in tissue $[1,2]$.

House dust mite (HDM) allergy is strongly implicated in the pathogenesis of respiratory allergic disease and a large proportion of patients with allergic rhinitis (AR), allergic asthma (AA), or both, are sensitized to HDM, predominantly Dermatophagoides pteronyssinus and Dermatophagoides farinae [3].

Efficacy of AIT in HDM allergy is documented by a number of controlled trials in adults and few controlled trials in children [1, 4]. Subcutaneous immunotherapy (SCIT) has been well investigated for individual preparations in controlled bronchial asthma as defined by the Global Initiative for Asthma (GINA) 2007 as well as in intermittent and mild persistent asthma (GINA 2005). AIT is recommended as a treatment option, in addition to allergen avoidance and pharmacotherapy in GINA 2017, provided there is a clear causal link between respiratory symptoms and the relevant allergen $[1,4,5]$.

The high-dose HDM allergoid is a depot formulation with aluminum hydroxide for subcutaneous AIT. Formaldehyde and glutaraldehyde have been used in combination to chemically modify an aqueous extract of purified HDM bodies and to produce a stable allergoid. The allergen extract consists of the HDM Dermatophagoides pteronyssinus or Dermatophagoides farinae alone or in combination. The product is manufactured at two different strengths, which enables a low initial dose and increasing concentration of allergens in the further course of treatment. In maintenance therapy, intervals of up to 8 weeks are very convenient and allow for flexibility. The marketed dose is 3000 protein nitrogen units (PNU) $/ \mathrm{mL}$ in strength B (strength A: $300 \mathrm{PNU} / \mathrm{mL}$ obtained by a 1:10 dilution of strength $\mathrm{B}$ ) with a max- imum injection volume of $0.6 \mathrm{ml}$ (1800 PNU; [8]). The major allergen content of the high-dose HDM allergoid D. pteronyssinus is $12 \mu \mathrm{q} / \mathrm{ml}$ Der $\mathrm{p} 1$ and $10 \mu \mathrm{g} / \mathrm{ml}$ Der $\mathrm{p}$ 2; for the high-dose HDM allergoid $D$. farinae it is $20 \mu \mathrm{g} / \mathrm{ml}$ Der f 1 and $15 \mu \mathrm{g} / \mathrm{ml}$ Der f 2 [9].

This HDM SCIT product has been shown to be effective in patients with mite-induced allergic asthma. Adding the mite allergoid SCIT to pharmacologic treatment was an effective and safe strategy to reduce corticosteroid doses while maintaining disease control and significantly improved bronchial allergen provocation (BAP; [6, 7]). There is however no data available comparing safety information for AIT products from clinical development and spontaneous safety reports from daily practice since launch, particularly not in different patient subgroups [10].

The publication presents safety data of this highdose HDM allergoid in clinical development and from adverse drug reactions (ADRs) spontaneously reported after launch, including subgroup analysis. SLIT is reported as having ADRs in $40-75 \%$ of the cases as temporary local mucosal reactions (pruritus or dysesthesia in the oral cavity, swelling of the oral mucosa, throat irritation) and considered as having a better safety profile than SCIT, especially with respect to systemic reactions, anaphylaxis, and other severe systemic reactions [1]. Therefore, the safety data of this product were compared to the safety of two different SLIT mite tablets as benchmark.

\section{Material and methods}

\section{Product}

The high-dose HDM allergoid (Acaroid ${ }^{\circledR}$ ) consists of the HDM Dermatophagoides pteronyssinus alone (used in Trials AL0104av (EudraCT: 2004-003892-35), 97-09 M, 97-09 UK, AL0106ac (EudraCT: 2006-00093411), and AL1009ac (EurdraCT: 2011-002248-29)) or in 1:1 combination with Dermatophagoides farinae (used in Trial AL0400av; Table 1). 97-09 M, 97-09 UK, and AL0400av were performed before introduction of the EudraCT database. The drug product is a suspension administered by subcutaneous injection.

The following strengths were used in Trials AL0104av, 97-09 M, 97-09 UK, AL0400av, and AL0106ac: strength B: $3000 \mathrm{PNU} / \mathrm{mL}$; strength A: $300 \mathrm{PNU} / \mathrm{mL}$ (obtained by a 1:10 dilution of strength $\mathrm{B}$ ). In the dose range finding trial AL1009ac 4 different doses were tested: $600 \mathrm{PNU} / \mathrm{mL}, 1800 \mathrm{PNU} / \mathrm{mL}, 3000 \mathrm{PNU} / \mathrm{mL}$ and $5400 \mathrm{PNU} / \mathrm{mL}$.

\section{Study population}

This publication presents safety information from 6 completed, randomized, controlled clinical trials conducted between 2000 and 2015 in patients with allergic rhinitis/rhinoconjunctivitis (97-09 M, 97-09 UK, AL0400av, and AL0106ac), patients with al- 
Table 1 Summary of the high-dose HDM allergoid clinical trials included in the pooled safety analysis

\begin{tabular}{|c|c|c|c|c|c|c|c|c|}
\hline \multirow[t]{3}{*}{ Study } & \multicolumn{2}{|l|}{ Population } & \multirow[t]{3}{*}{ Treatment } & \multirow[t]{3}{*}{$n$} & \multicolumn{4}{|c|}{ Included in safety set of } \\
\hline & Indication & Age (years) & & & HDM-ALL & HDM-DBPC & HDM-RCT(UC) & Placebo \\
\hline & & & & & $(n=279)$ & $(n=214)$ & $(n=65)$ & $(n=221)$ \\
\hline \multirow[t]{2}{*}{$97-09 \mathrm{M}^{\mathrm{a}}$} & \multirow[t]{2}{*}{ Allergic rhinitis/rhinoconjunctivitis } & \multirow[t]{2}{*}{$18-58$} & 1800 PNU & 20 & Yes & Yes & - & - \\
\hline & & & Placebo & 20 & - & - & - & Yes \\
\hline \multirow[t]{2}{*}{ 97-09 UK } & \multirow[t]{2}{*}{ Allergic rhinitis/rhinoconjunctivitis } & \multirow[t]{2}{*}{$22-54$} & $1800 \mathrm{PNU}$ & 15 & Yes & Yes & - & - \\
\hline & & & Placebo & 15 & - & - & - & Yes \\
\hline \multirow{2}{*}{$\begin{array}{l}\text { AL0106ac } \\
\text { EudraCT: } \\
\text { 2006-000934-11 }\end{array}$} & \multirow[t]{2}{*}{ Allergic rhinitis/rhinoconjunctivitis } & \multirow[t]{2}{*}{$19-46$} & 1800 PNU & 51 & Yes & Yes & - & - \\
\hline & & & Placebo & 57 & - & - & - & Yes \\
\hline \multirow[t]{2}{*}{ Al0400av } & \multirow[t]{2}{*}{ Allergic rhinitis/rhinoconjunctivitis } & \multirow[t]{2}{*}{$18-54$} & $1800 \mathrm{PNU}$ & 69 & Yes & Yes & - & - \\
\hline & & & Placebo & 66 & - & - & - & Yes \\
\hline \multirow{5}{*}{$\begin{array}{l}\text { Al1009ac } \\
\text { EurdraCT: } \\
\text { 2011-002248-29 }\end{array}$} & \multirow{5}{*}{$\begin{array}{l}\text { Controlled allergic bronchial asthma } \\
\text { and rhinitis/rhinoconjunctivitis }\end{array}$} & \multirow[t]{5}{*}{$18-40$} & $600 \mathrm{PNU}$ & 24 & - & - & - & - \\
\hline & & & 1800 PNU & 31 & Yes & Yes & - & - \\
\hline & & & $3000 \mathrm{PNU}$ & 28 & - & - & - & - \\
\hline & & & 5400 PNU & 31 & - & - & - & - \\
\hline & & & Placebo & 32 & - & - & - & Yes \\
\hline \multirow{6}{*}{$\begin{array}{l}\text { AL0104av } \\
\text { EudraCT: } \\
\text { 2004-003892-35 }\end{array}$} & \multirow{6}{*}{$\begin{array}{l}\text { Allergic asthma with or without } \\
\text { allergic rhinitis/rhinoconjunctivitis }\end{array}$} & $6-406-40$ & - & - & - & - & - & - \\
\hline & & $\geq 18$ & 1800 PNU & 28 & Yes & Yes & - & - \\
\hline & & $\geq 18$ & Placebo & 31 & - & - & - & Yes \\
\hline & & $<12$ & 1800 PNU & 39 & Yes & - & Yes & - \\
\hline & & $12-17$ & $1800 \mathrm{PNU}$ & 26 & Yes & - & Yes & - \\
\hline & & $6-17$ & Usual care & 32 & - & - & - & - \\
\hline
\end{tabular}

lergic asthma and allergic rhinitis/rhinoconjunctivitis (Trial AL1009ac), or subjects with allergic asthma with or without allergic rhinitis/rhinoconjunctivitis (Trial AL0104av). Demographic details are shown in Table 2. We present safety information from patients treated with the marketed dose of 1800 PNU $(n=279)$ as maintenance dose $(100 \%$ D. pteronyssinus or $50 \% / 50 \%$ D. pteronyssinus/D. farinae allergens/ mixtures). The maximum treatment duration was 3 years and 2 years with placebo, respectively; the maximum double-blind, placebo-controlled treatment phase was 2 years (97-09 M, 97-09 UK, AL0400av, and AL0106ac, AL0104av adults). In study AL0104av, children and adolescents $(n=65 ; 6-17$ years) with asthma were treated for up to 3 years with this HDM AIT (Group: HDM-RCT(UC)).

\section{Safety sets}

Subjects of the double-blind placebo controlled (DBPC) safety set who received at least 1 dose of the trial drug during the double-blind treatment period with $1800 \mathrm{PNU}$ or placebo were combined (Trials AL1009ac, AL0104av, 97-09 M, 97-09 UK, AL0106ac, and AL0400av) in group HDM-DBPC $(n=214)$. The safety set HDM-ALL consists of patients from the DBPC phase plus patients from the asthma versus usual care trial $(n=279$; Table 1$)$.
Subgroups: The following subgroups were performed:

- Age group $(<12,12-17, \geq 18$ years)

- Gender (female/male)

- Subjects with asthmatic symptoms (Global Initiative for Asthma classification >0, GINA, 2006). Classification was assessed in Trials AL1009ac, AL0104av, AL0106ac, and AL0400av.

Spontaneous safety reports: For the period after launch of the product (01 July 2005) to 31 March 2016, ADRs were calculated in relation to the number of products sold and patients treated and classified according to expectedness. For unexpected ADRs, the system organ classes (SOCs) were reported.

\section{Coding of treatment-related AEs (TRAES):}

AEs were coded using the MedDRA version 15.0. AEs with onset during or after the first administration of the trial drug were defined as TRAEs. An AE was defined as being related to the trial drug if the causal relationship of the $\mathrm{AE}$ was assessed as "at least possible". 
Table 2 Demographics and baseline characteristics

\begin{tabular}{|c|c|c|c|c|c|c|c|c|}
\hline & Statistics & $\begin{array}{l}97-09 \mathrm{M} \\
(n=20)\end{array}$ & $\begin{array}{l}97-09 \text { UK } \\
(n=15)\end{array}$ & $\begin{array}{l}\text { AL0104av } \\
(n=93)\end{array}$ & $\begin{array}{l}\text { AL0106ac } \\
(n=51)\end{array}$ & $\begin{array}{l}\text { AL0400av } \\
(n=69)\end{array}$ & $\begin{array}{l}\text { AL1009ac } \\
(n=114)\end{array}$ & $\begin{array}{l}\text { Total } \\
(n=362)\end{array}$ \\
\hline \multirow[t]{2}{*}{ Age (years) } & Mean (SD) & $29.4(10.0)$ & $36.9(10.4)$ & $15.2(8.9)$ & $29.6(8.0)$ & $27.6(9.3)$ & $27.3(6.6)$ & $25.1(10.3)$ \\
\hline & Min-Max & $18.0-58.0$ & $22.0-54.0$ & $6.0-40.0$ & $19.0-46.0$ & $18.0-54.0$ & $18.0-40.0$ & $6.0-58.0$ \\
\hline \multirow[t]{2}{*}{ Gender ( $n[\%])$} & Female & $5(25.0)$ & $10(66.7)$ & $33(35.5)$ & $24(47.1)$ & $29(42.0)$ & $49(43.0)$ & $150(41.4)$ \\
\hline & Male & $15(75.0)$ & $5(33.3)$ & $60(64.5)$ & 27 (52.9) & $40(58.0)$ & $65(57.0)$ & 212 (58.6) \\
\hline \multirow[t]{3}{*}{ Age group ( $n$ [\%]) } & $<12$ & $0(0.0)$ & $0(0.0)$ & $39(41.9)$ & $0(0.0)$ & $0(0.0)$ & $0(0.0)$ & $39(10.8)$ \\
\hline & $12-17$ & $0(0.0)$ & $0(0.0)$ & $26(28.0)$ & $0(0.0)$ & $0(0.0)$ & $0(0.0)$ & $26(7.2)$ \\
\hline & $\geq 18$ & $20(100.0)$ & $15(100.0)$ & $28(30.1)$ & $51(100.0)$ & $69(100.0)$ & $114(100.0)$ & $297(82.0)$ \\
\hline \multirow[t]{2}{*}{ Smoking status ( $n$ [\%]) } & Smoker & $4(20.0)$ & $0(0.0)$ & $0(0.0)$ & $5(9.8)$ & 18 (26.1) & $1(0.9)$ & $28(7.7)$ \\
\hline & Nonsmoker & $16(80.0)$ & $15(100.0)$ & $93(100.0)$ & $46(90.2)$ & 51 (73.9) & 113 (99.1) & 334 (92.3) \\
\hline \multirow[t]{2}{*}{ Asthma ( $n[\%])$} & Yes & - & - & $93(100.0)$ & $26(51.0)$ & $34(49.3)$ & $114(100.0)$ & 267 (73.8) \\
\hline & No & - & - & $0(0.0)$ & $25(49.0)$ & $35(50.7)$ & $0(0.0)$ & 60 (16.6) \\
\hline \multirow{5}{*}{$\begin{array}{l}\text { GINA classification } \\
(n[\%])\end{array}$} & GINA I & - & - & $0(0.0)$ & $14(27.5)$ & $18(26.1)$ & - & $32(8.8)$ \\
\hline & GINA II & - & - & 76 (81.7) & $12(23.5)$ & $16(23.2)$ & - & 104 (28.7) \\
\hline & GINA III & - & - & 17 (18.3) & $0(0.0)$ & $0(0.0)$ & - & $17(4.7)$ \\
\hline & GINA IV & - & - & $0(0.0)$ & $0(0.0)$ & $0(0.0)$ & - & $0(0.0)$ \\
\hline & No asthma & - & - & $0(0.0)$ & $25(49.0)$ & $35(50.7)$ & - & 60 (16.6) \\
\hline \multirow{3}{*}{$\begin{array}{l}\mathrm{FEV}_{1} \text { or PEF } \\
\text { (\% of predicted value) }\end{array}$} & $n$ & - & - & 93 & 51 & 69 & 61 & 274 \\
\hline & Mean (SD) & - & - & $93.1(10.6)$ & $101.8(15.2)$ & $104.2(14.2)$ & $98.7(9.8)$ & $98.8(13.1)$ \\
\hline & Min-Max & - & - & $80.0-139.0$ & $80.1-135.7$ & $75.0-147.0$ & $82.2-123.8$ & $75.0-147.0$ \\
\hline \multirow{3}{*}{$\begin{array}{l}\text { Duration of allergic } \\
\text { rhinoconjunctivitis } \\
\text { (years) }\end{array}$} & $n$ & 20 & 15 & 77 & 51 & 69 & 114 & 346 \\
\hline & Mean (SD) & $5.8(3.2)$ & $21.1(10.1)$ & $5.7(5.1)$ & $12.5(8.6)$ & $8.6(7.8)$ & $8.2(5.8)$ & $8.8(7.4)$ \\
\hline & Min-Max & $2.0-13.0$ & $2.0-40.0$ & $1.0-20.0$ & $2.0-39.0$ & $1.0-45.0$ & $0.0-24.0$ & $0.0-45.0$ \\
\hline
\end{tabular}

\section{Results}

\section{Clinical development}

In all, 362 subjects (children, adolescents, adults) have received at least 1 dose of active treatment in the completed trials of the high-dose HDM allergoid clinical development program (Table 1) - 114 subjects in the dose finding trial, 93 subjects in the allergic asthma trial, and 155 subjects in the allergic rhinitis/ rhinoconjunctivitis trials. A total of 297 patients were treated with this HDM AIT during the DBPC period of the trials, 221 subjects with placebo. In children/ adolescents, the trial drug was administered in an open-label design and usual care was used as control instead of placebo $(n=65)$.

\section{Marketed dose in clinical development}

A total of 279 subjects received the marketed dose of 1800 PNU $(0.6 \mathrm{ml}$ strength B). The median number of injections administered in the 1800 PNU group was 15 injections during the $1^{\text {st }}$ treatment year (placebo: 15 injections), 12 injections during the $2^{\text {nd }}$ treatment year (placebo: 12 injections), and 8 injections during the $3^{\text {rd }}$ treatment year. The reasons for the difference in injection numbers are the up-dosing phase in year one and the possible prolongation of treatment intervals up to 8 weeks during maintenance treatment. In all, 148 patients received 1800 PNU for $>2$ years. Overall, 267 patients in the clinical development program of this HDM AIT had asthma: GINA I $n=32$, GINA II $n=104$, and GINA III $n=17$ (114 patients without GINA classification). Patients had rhinoconjunctivitis for a mean of 8.8 (SD 7.4) years, min. 2-max. 45 years. A total of 65 patients were less than 18 years of age (only included in the asthma trial, Trial AL0104av): $<12$ years $(n=39), 12-17$ years $(n=26$; Table 1$)$.

\section{Safety of marketed dose in clinical development}

In all, 214 patients received the 1800 PNU during the DBPC phase of the different trials and 65 in the asthma versus usual care trial (RCT(UC); Table 1), whereby $38.8 \%$ of patients treated with HDM AIT had an adverse event related to the trial drug, compared to $31.2 \%$ with placebo and $35.5 \%$ of the HDM AIT patients in the HDM-ALL group (Fig. 1). The difference in adverse events related to the study drug was primarily because of local reactions; there was no difference in the share of patients with systemic reactions $(10.9 \%$ placebo, $11.2 \%$ HDM-DBPC, $11.1 \%$ HDM-All). One out of 279 patients in the HDMAll group experienced a serious adverse event (SAE): hospitalization because of erythema, conjunctivitis, asthma, cough, cyanosis, urticaria, and wheezing $15 \mathrm{~min}$ after administration of the trial drug during the $3^{\text {rd }}$ treatment year. The event resolved on the 


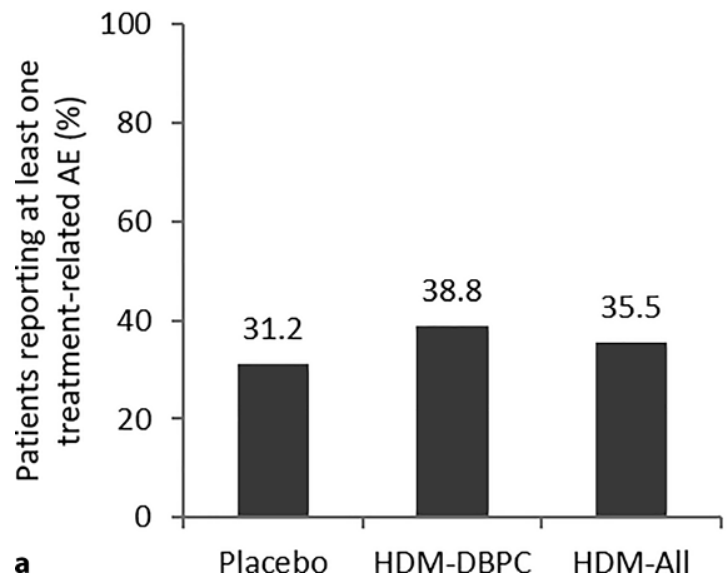

Fig. 1 Percentage of patients reporting treatment-related adverse events related to study drug: $\mathbf{a}$ in the different treatment groups: placebo, HDM-DBPC, and HDM-All. b Distribution according to local, systemic and serious adverse event (AE). (DBPC Phase: placebo $n=221$, HDM DBPC $n=214$;

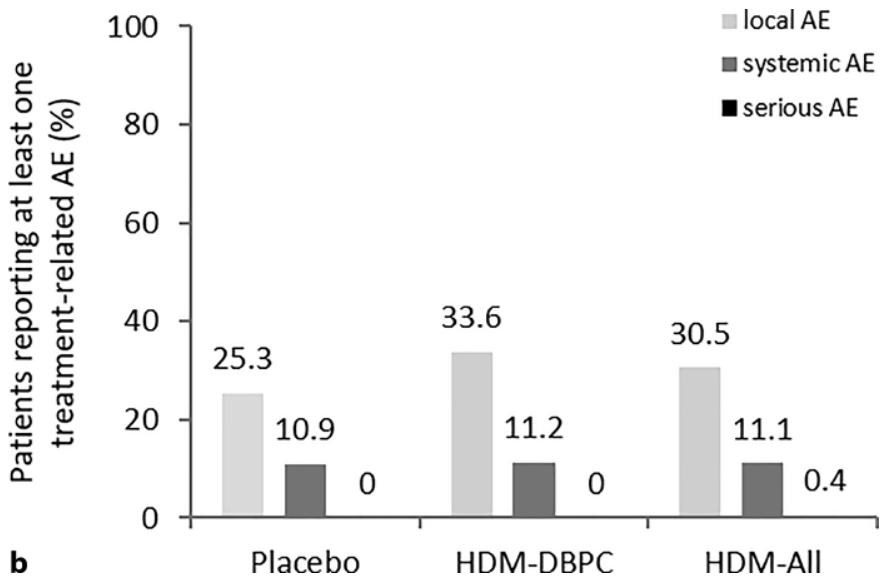

HDM-All $n=279$ ). HDM-DBPC high-dose HDM allergoid AIT double-blind placebo controlled, HDM-RCT(UC) high-dose HDM allergoid AIT usual care controlled, HDM-ALL HDMDBPC plus HDM-RCT(UC), $A E$ adverse event
Table 3 Treatment-related adverse events related to the trial drug reported in $>2 \%$ of subjects by PT in decreasing frequency

\begin{tabular}{llll}
\multicolumn{5}{l}{ Number (\%) subjects } \\
& DBPC Phase & & \\
& Placebo & HDM DBPC & HBPC plus RCT(UC) \\
& $(N=221)$ & $(N=214)$ & $(N=279)$ \\
\hline & $69(31.2)$ & $83(38.8)$ & $99(35.5)$ \\
\hline Subjects with related treatment-emergent AE & $51(23.1)$ & $61(28.5)$ & $71(25.4)$ \\
\hline Injection site swelling & $11(5.0)$ & $25(11.7)$ & $31(11.1)$ \\
\hline Injection site pruritus & $4(1.8)$ & $16(7.5)$ & $17(6.1)$ \\
\hline Injection site erythema & $5(2.3)$ & $9(4.2)$ & $15(5.4)$ \\
\hline Injection site pain & $5(2.3)$ & $7(3.3)$ & $8(2.9)$ \\
\hline Rhinitis & $0(0.0)$ & $7(3.3)$ & $7(2.5)$ \\
\hline Pruritus & $2(0.9)$ & $6(2.8)$ & $8(2.9)$ \\
\hline Cough & $6(2.7)$ & $1(0.5)$ & $1(0.4)$ \\
\hline Sneezing & $3(1.4)$ & $2(0.9)$ & $6(2.2)$ \\
\hline Rhinitis allergic & $1(0.5)$ & $5(2.3)$ & $5(1.8)$ \\
\hline Fatigue & & & \\
\hline $\begin{array}{l}\text { DBPC double-blind placebo controlled, } R C T(U C) \\
\text { double-blind placebo controlled, } H D M-R C T(U C) \text { high-dose HDM allergoid AIT usual care controlled, HDM-ALL HDM-DBPC } \\
\text { plus HDM-RCT(UC), AE adverse event }\end{array}$ & & & \\
\hline
\end{tabular}

same day. Exacerbations of asthma were mentioned in the medical history. The patient was treated with an inhaled corticosteroid dose of $200 \mu \mathrm{g}$ fluticasone as asthma controller medication that was reduced to $100 \mu \mathrm{g} 4$ weeks before the SAE. No SAEs were observed in placebo or HDM-DBPC group.

An overview about the TRAEs related to the trial drug and reported in $>2 \%$ of patients is presented in Table 3.

Clinical laboratory measurements (biochemistry, hematology, and urinalysis) were analyzed in most of the trials. A shift of normal at baseline to abnormal after treatment was reported for $>5 \%$ of subjects in any group only for eosinophils and neutrophils (14 subjects with HDM AIT). There were no other noteworthy differences between the groups.

\section{Subgroup analysis}

A summary of TRAEs by subgroups-age $(a, b)$, gender (c, d), asthma status (e, f)-is presented in Fig. 2. Children and adolescents had fewer related adverse events and local reactions compared to adults; systemic reactions were slightly more frequent in children $(12.8 \%$ versus $11.2 \%$ in adults), but much lower in adolescents $(7.7 \%)$. Females had more adverse events in all 4 groups compared to males (see Fig. 2c, d). Treatment was well tolerated in asthmatic patients and the number of related adverse event, local reactions, and systemic reactions were low (see Fig. 2e, f), but one SAE occurred. 
Table 4 Safety overview of the high-dose HDM allergoid versus SLIT mite tablets

\begin{tabular}{|c|c|c|c|}
\hline \multirow[t]{2}{*}{ Product } & \multicolumn{3}{|c|}{$\begin{array}{l}\text { ADRs with at least possible relationship to study } \\
\text { drug (\%) }\end{array}$} \\
\hline & Rhinoconjunctivitis \pm & Asthma & $\begin{array}{l}\text { Pediatrics with } \\
\text { asthma } \\
\text { (12-17 years) }\end{array}$ \\
\hline \multicolumn{4}{|l|}{ HDM allergoid } \\
\hline $\begin{array}{l}1800 \text { PNU high- } \\
\text { dose HDM allergoid }\end{array}$ & 38.8 & 23.9 & 19.2 \\
\hline Placebo & 31.2 & 18.0 & - \\
\hline \multicolumn{4}{|c|}{ HDM SLIT tablet $[12,14-16]$} \\
\hline $6 \mathrm{SQ}-\mathrm{HDM}$ & 48 & 39 & 55 \\
\hline 12 SQ-HDM & $53 / 50$ & 46 & 50 \\
\hline Placebo & $15 / 16$ & 17 & 32 \\
\hline \multicolumn{4}{|l|}{ HDM SLIT tablet [13] } \\
\hline $300 \mathrm{IR}$ & 66.8 & - & - \\
\hline $500 \mathrm{IR}$ & 73.1 & - & - \\
\hline Placebo & 18.6 & - & - \\
\hline
\end{tabular}

\section{Spontaneous safety reports}

In the period from the first market launch (01 July 2005) to 31 March 2016 more than hundred thousand patients were treated with HDM AIT 1800 PNU as maintenance dose. ADRs were reported in $0.5 \%$ of patients compared to $38.8 \%$ (HDM-DBPC) and $35.5 \%$ (HDM-ALL) in clinical development; $94.6 \%$ of these ADRs were expected. The unexpected events were primarily reported in the SOCs: nervous system disorders (headache, hypoesthesia, paresthesia); musculoskeletal and connective tissue disorders (arthralgia, myalgia, pain in extremity); general disorders and administration site conditions (pyrexia); gastrointestinal disorders (oral mucosal blistering, nausea, gastrointestinal pain); and skin and subcutaneous tissue disorders (alopecia, eczema). No special patient group could be identified to be at higher risk, and no safety concern has arisen from this received post marketing safety data.

\section{Subgroup analysis of spontaneous safety reports}

In the period from the first market launch to 31 March 2016 several ten thousand children and adolescents were also treated with HDM AIT 1800 PNU. ADRs were reported in $0.9 \%$ of children $(0-11$ years of age), $0.6 \%$ of adolescents (12-17 years) compared to $0.3 \%$ in adults ( $\geq 18$ years).

If we assume that $50 \%$ female and $50 \%$ male patients were treated after launch, the number of ADRs were comparable irrespective of gender (female $0.4 \%$, male $0.5 \%)$. The same was true for asthma. Asthma is found in up to $38 \%$ of patients with allergic rhinitis [11]. With this HDM AIT SCIT $0.4 \%$ of ADR reports were in patients with asthma and $0.5 \%$ in non-asthmatics.

\section{Discussion}

In recent years, publications on HDM immunotherapy focused on sublingual treatment. Several multinational, randomized, placebo-controlled clinical trials of high quality standards in different patient populations and subgroups are available. In addition, this treatment route is known to be safe, which is why we compared our data with relevant data of sublingual products recently published in international literature.

\section{Rhinoconjunctivitis}

In our observation of patients with rhinoconjunctivitis with/without asthma, adverse events with at least possible relationship to the high-dose HDM allergoid were $38.8 \%$ compared to $31.2 \%$ with placebo. This is lower than the, at least possibly, related adverse events seen in allergic rhinitis patients treated with HDM SLIT tablet (48.0\% 6 SQ-HDM, 53.0\% 12 SQHDM, $15.0 \%$ placebo; [12]; Table 4). The related AEs were primarily local reactions $(33.6 \%)$ in HDM SCIT (injection site swelling $28.5 \%$, -pruritus $11.7 \%$, -erythema $7.5 \%$, -pain $4.2 \%$ ). This is comparable to the safety profile of HDM SLIT where the most common AEs are reported as being related to the investigational medicinal product (IMP) by the investigator were oral pruritus, throat irritation, and mouth edema (20.0, 14.0 , and $8.0 \%$ of subjects on active treatment, respectively; [12]). In a recently published double-blind trial, evaluating the efficacy and safety of HDM tablets in 968 adolescent and adult patients (aged 12-64 years) with HDM-induced AR with or without intermittent asthma over 52 weeks, the number of subjects with any adverse drug reaction was $66.8 \%$ with the recommended dose 300 IR $(73.1 \%$ with 500 IR), and $18.6 \%$ with placebo [13]. In two pooled RC clinical trials with 1215 subjects (12 SQ HDM tablet $n=600,615$ placebo) with a clinical history of HDM allergic rhinitis, and $863(71 \%)$ with additional HDM allergic asthma 50\% of subjects on active treatment reported TRAEs compared to $16 \%$ of subjects on placebo [14].

\section{Asthma}

HDM is the most common allergen associated with asthma and more than $40 \%$ of adult asthmatics are atopic with a positive skin prick test result for the HDM allergens [15]. Adverse events related to the high-dose HDM allergoid were $23.9 \%$ in the group of patients with asthma compared to $46.7 \%$ in patients without asthma, placebo $18 \%$; subjects with TRAEs were $47.9 \%$ compared to $51.6 \%$ with placebo. In a recently published study of asthma patients with a sublingual HDM tablet, AIT TRAEs occurred in 
Fig. 2 Percentage of patients reporting treatmentrelated adverse events related to study drug analyzed in different subgroups: age $(\mathbf{a}, \mathbf{b})$, gen$\operatorname{der}(\mathbf{c}, \mathbf{d})$, asthma status $(\mathbf{e}, \mathbf{f})$. a Data are shown for HDMDBPC ( $\geq 18$ years) and HDMRCT(UC) (12-17 years and $<12$ years). b Distribution according to local, systemic and serious $\mathrm{AE}$. c Percentage of female and male patients in HDMAll reporting a treatmentrelated $\mathrm{AE}$. d Distribution according to local, systemic and serious AE. e Percentage of patients with and without asthma reporting a treatment-related $\mathrm{AE}$ and f Distribution according to local, systemic and serious AE. (Age (a, b): $\geq 18$ years $n=214,12-17$ years $n=26$, $<12$ years $n=39$; Gender $(\mathbf{c}, \mathbf{d})$ : female $n=115$, male $n=164$; Asthma status (e, f): no asthma symptom $n=60$, any asthma symptom $n=184$ ). HDM-DBPC high-dose HDM allergoid AIT double-blind placebo controlled, HDMRCT(UC) high-dose HDM allergoid AIT usual care controlled, HDM-ALL HDMDBPC plus HDM-RCT(UC), $A E$ adverse event, $y r s$ years
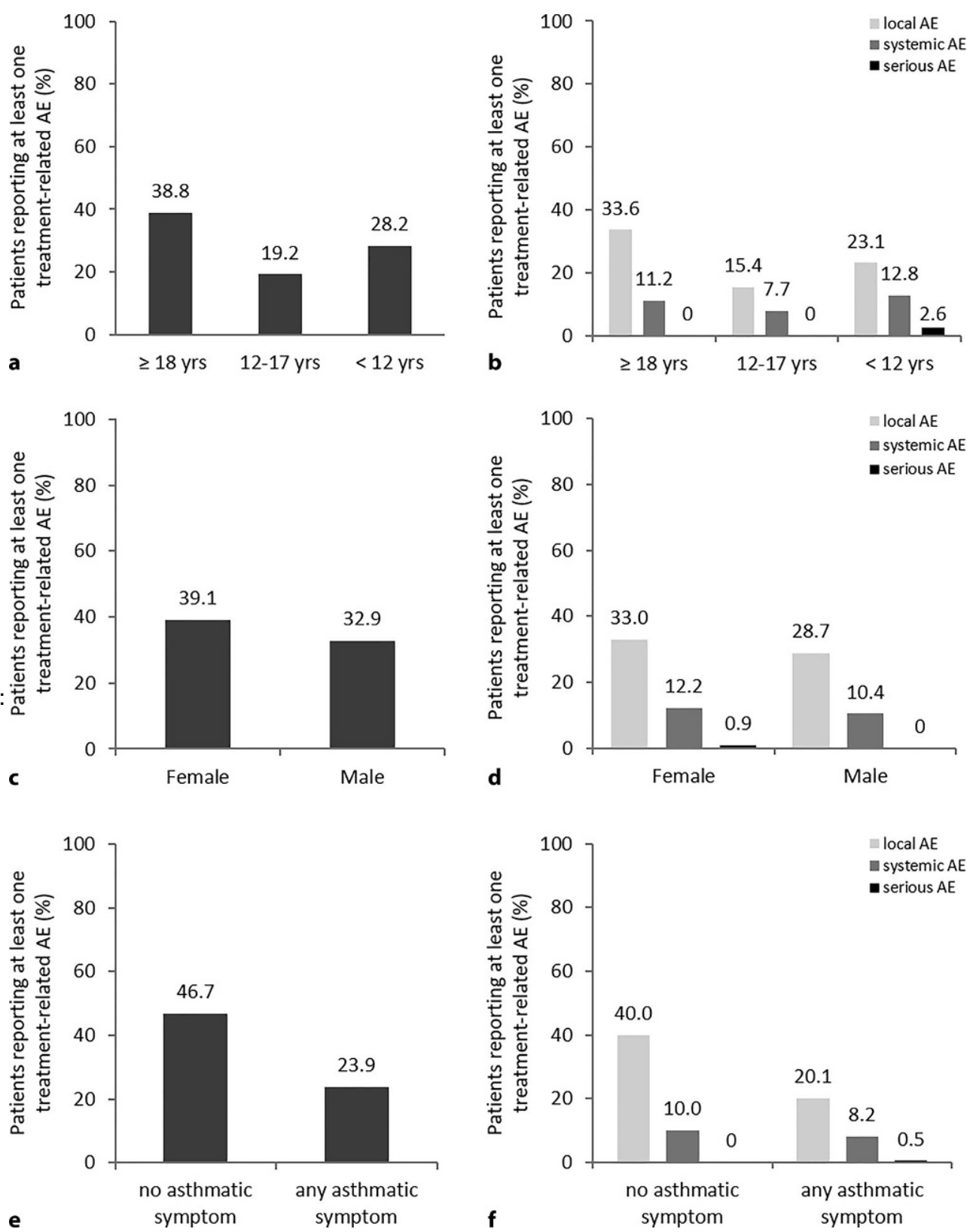

$39.0 \%$ in the 6 SQ-HDM group, $46.0 \%$ in the 12 SQHDM group, and $17.0 \%$ with placebo [14]. A possibly treatment-related serious adverse event was reported for the 12 SQ-HDM tablet: asthma (moderate, alternative etiology was "recently viral infection"; [15]). With the high-dose HDM allergoid a serious adverse event (erythema, conjunctivitis, asthma, cough, cyanosis, urticaria, wheezing) was reported in an asthmatic child $15 \mathrm{~min}$ after administration of trial drug. Exacerbations of asthma were mentioned in the medical history and the corticosteroid dose was reduced from $200 \mu \mathrm{g}$ fluticasone to $100 \mu \mathrm{g} 4$ weeks before the SAE. These examples show how important it is that asthma is controlled, especially when an AIT is performed and guidelines are followed.

\section{Pediatrics}

There is little data available about the safety of HDM AIT in children and adolescents. In a recently published multicenter, double-blinded, randomized trial in adolescents (12-17 years old) with HDM allergic rhinitis with and without conjunctivitis and with or without asthma, patients received placebo, HDM SLIT tablet 6 SQ or 12 SQ once daily for 28 days. The proportion of subjects who experienced TRAEs was $25.0 \%, 45.0 \%$, and $52.0 \%$ for the placebo, 6 SQHDM, and 12 SQ-HDM groups, respectively [16]. With the high-dose HDM allergoid, TRAEs were observed in $19.2 \%$ of adolescents (12-17 years old). There was a greater incidence of TRAEs in adolescents with asthma receiving the HDM SLIT tablet compared with placebo (asthma: $32.0 \%, 55.0 \%, 50.0 \%$, placebo, 6-SQ, 
12-SQ respectively; without asthma: $21.0 \%, 40.0 \%$, $54.0 \%$; [16]). In the high-dose HDM allergoid group of adolescents, all had asthma and received the trial drug for up to two years (28 days for HDM SLIT).

\section{Gender}

No literature is available about safety differences of HDM immunotherapy in females versus males. In the clinical development program of the HDM SCIT allergoid we observed a few more related AEs in females $(39.1 \%)$ compared to males $(32.9 \%)$, but more data are needed.

\section{Spontaneous safety reports}

The safety of a medicinal product after launch in daily practice with much higher numbers of treated patients and a broad range of different patients treated adds to the safety information of a product. Very rare side effects might be seen for the first time and unexpected side effects might be reported. With the HDM SCIT product presented in this publication, adverse drug reactions were reported in $0.5 \%$ of patients compared to $38.8 \%$ (HDM-DBPC) and $35.5 \%$ (HDM-ALL) in clinical development, whereby $94.6 \%$ of these ADRs were expected, and there was no major concern about the unexpected ADRs related to the safety of this SCIT product in daily routine.

\section{Pediatric data analyzed from spontanous safety reports}

Compared to adults slightly more children and adolescents $(0.9 \%$ children, $0.6 \%$ adolescents, $0.3 \%$ adults $)$ experienced an ADR. This is based on a great database of several thousand treated patients and possibly a higher reporting rate of ADRs in younger age groups. No new safety information has arisen concerning system organ classes or preferred terms of the reported ADRs.

\section{Gender data analyzed from spontanous safety reports}

According to post marketing safety data no gender specific safety difference could be identified (female $0.4 \%$, male $0.5 \%$ ), and the high-dose HDM allergoid is well tolerated in asthmatic as well as non-asthmatic patients $(0.4 \%$ asthma, $0.5 \%$ non-asthma patients with ADR).

On the basis of more than hundred thousand treated patients with the high-dose HDM allergoid in daily routine and a broad range of different patient groups, no special patient group could be identified to be at higher risk, no safety concern has arisen from the unexpected ADRs and the safety was comparable to what was already known from clinical development.

\section{Conclusion}

Subcutaneous treatment with the high-dose HDM allergoid was well tolerated in HDM respiratory allergic disease in clinical development. The observed difference to placebo was primarily driven by local reactions; there was no difference in systemic reactions. The high-dose HDM allergoid was also well tolerated in daily practice. As $95 \%$ of ADRs were expected, no safety concern has arisen from the post marketing safety data. The product was well tolerated in all age groups (children, adolescents, and adults), in asthmatics and non-asthmatics. Furthermore, the safety profile was comparable to HDM SLIT tablets.

Acknowledgements The authors like to thank Annemie Narkus, MC Narkus Medical Consulting + Services, Bleckede, Germany for medical writing and Jacqueline Alig, Allergopharma $\mathrm{GmbH} \&$ Co. $\mathrm{KG}$, for intensive discussions on the results and the way of their presentation.

Funding Financial support for the development of this article was provided by Allergopharma GmbH \& Co. KG. Allergopharma $\mathrm{GmbH} \&$ Co. KG designed and provided funding for the studies described in this article.

Conflict of interest L. Klimek has received research grants from ALK-Abelló, Denmark; Allergopharma, Germany; Bionorica, Germany; Biomay, Austria, Boehringer Ingelheim, Germany, Circassia, USA; Stallergenes, France; HAL, Netherlands; Allergy Therapeutics/Bencard, Great Britain/Germany; Hartington, Spain; Lofarma, Italy; MEDA, Sweden; Novartis, Switzerland, Leti, Spain; ROXALL, Germany; Glaxo-SmithKline (GSK), Great Britain; Cytos, Switzerland; Curalogic, Denmark; and/or has served on the speaker's bureau or was consulting for the above mentioned pharmaceutical companies. G.-C. Fox and S. Thum-Oltmer are employees of Allergopharma GmbH \& Co. KG, Reinbek, Germany.

Open Access This article is distributed under the terms of the Creative Commons Attribution 4.0 International License (http://creativecommons.org/licenses/by/4.0/), which permits unrestricted use, distribution, and reproduction in any medium, provided you give appropriate credit to the original author(s) and the source, provide a link to the Creative Commons license, and indicate if changes were made.

\section{References}

1. PfaarO, BachertC, BufeA, BuhlR, EbnerC,EngP, etal. Guideline on allergen-specific immunotherapy in IgE-mediated allergic diseases: S2kGuideline of the GermanSocietyforAllergology and Clinical Immunology (DGAKI), the Society for Pediatric Allergy and Environmental Medicine (GPA), the Medical Association of German Allergologists (AeDA), the Austrian Society for Allergy and Immunology (OGAI), the Swiss Society for Allergy and Immunology (SGAI), the German Society of Dermatology (DDG), the German Society of Oto-Rhino-Laryngology, Head and Neck Surgery (DGHNOKHC), the German Society of Pediatrics and Adolescent Medicine (DGKJ), the Society for Pediatric Pneumology (GPP), the German Respiratory Society (DGP), the German Association of ENT Surgeons (BV-HNO), the Professional Federation of Paediatricians and Youth Doctors (BVKJ), the Federal Association of Pulmonologists (BDP) and the 
German Dermatologists Association (BVDD). Allergo J Int. 2014;23:282-319.

2. Roberts G, Pfaar O, Akdis CA, Ansotegui IJ, Durham SR, Gerth van Wijk R, et al. EAACI guidelines on allergen immunotherapy: allergic rhinoconjunctivitis. Allergy. 2017; https://doi.org/10.1111/all.13317.

3. Calderon MA, Kleine-Tebbe J, Linneberg A, De Blay F, Hernandez Fernandez de Rojas D, Virchow JC, et al. House dust mite respiratory allergy: an overview of current therapeutic strategies. J Allergy Clin Immunol Pract. 2015;3:843-55.

4. Global strategy for asthma management and prevention. https:/ / www.ginasthma.org. 2017. Accessed 02/01/2018

5. Dhami S, Nurmatov U, Agache I, Lau S, Muraro A, Jutel M, et al. Allergen immunotherapy for allergic asthma: protocol for a systematic review. Clin Transl Allergy. 2015;6:5.

6. Zielen S, Kardos P, Madonini E. Steroid-sparing effects with allergen-specific immunotherapy in children with asthma: a randomized controlled trial. J Allergy Clin Immunol. 2010;126(5):942-9.

7. Rosewich M, Arendt S, El Moussaoui S, Schulze J, Schubert $\mathrm{R}$,ZielenS. Bronchial allergen provocation: ausefulmethod to assess the efficacy of specificimmunotherapyin children. Pediatr Allergy Immunol. 2013;24:434-40.

8. Allergopharma. Summary of product characteristics, Acaroid ${ }^{\circledR}$ Milbenpräparate. 2017.

9. Brehler R, Kahlert H, Thum-Oltmer S. Hypoallergene Präparate in der SCIT. Allergo J Int. 2010;19:477-84.

10. van der Valk JP, de Jong NW, Gerth van Wijk R. Review on immunotherapy in airway allergen sensitised patients. Neth J Med. 2015;73:263-9.
11. Brozek JL, Bousquet J, Agache I, Agarwal A, Bachert C, Bosnic-Anticevich S, et al. Allergic Rhinitis and its Impact on Asthma (ARIA) guidelines-2016 revision. J Allergy Clin Immunol. 2017;140:950-8.

12. Demoly P, Emminger W, Rehm D, Backer V, Tommerup L, Kleine-Tebbe J. Effective treatment of house dust miteinduced allergic rhinitis with 2 doses of the SQ HDM SLIT-tablet: results from a randomized, double-blind, placebo-controlled phase III trial. J Allergy Clin Immunol. 2016;137:444-451.e8.

13. Okamoto Y, Fujieda S, Okano M, Yoshida Y, Kakudo S, Masuyama K. House dust mite sublingual tablet is effective and safe in patients with allergic rhinitis. Allergy. 2017;72:435-43.

14. Emminger W, Hernandez MD, Cardona V, Smeenk F, Fogh BS, Calderon MA, et al. The SQ house dust mite SLIT-tablet is well tolerated in patients with house dust mite respiratory allergic disease. Int Arch Allergy Immunol. 2017;174:35-44.

15. Virchow JC, Backer V, Kuna P, Prieto L, Nolte H, Villesen $\mathrm{HH}$, et al. Efficacy of a house dust mite sublingual allergen immunotherapy tablet in adults with allergic asthma: a randomized clinical trial. JAMA. 2016;315:1715-25.

16. Maloney J, Prenner BM, Bernstein DI, Lu S, Gawchik S, Berman G, et al. Safety of house dust mite sublingual immunotherapy standardized quality tablet in children allergic to house dust mites. Ann Allergy Asthma Immunol. 2016;116:59-65. 